University of Nebraska - Lincoln

DigitalCommons@University of Nebraska - Lincoln

Feeding Fitness and Quality of Domesticated and Feral Predators: Effects of Long-Term Rearing on Artificial Diet

Allen Carson Cohen

USDA

Follow this and additional works at: https://digitalcommons.unl.edu/usdaarsfacpub

Part of the Agricultural Science Commons

Cohen, Allen Carson, "Feeding Fitness and Quality of Domesticated and Feral Predators: Effects of LongTerm Rearing on Artificial Diet" (2000). Publications from USDA-ARS / UNL Faculty. 343.

https://digitalcommons.unl.edu/usdaarsfacpub/343

This Article is brought to you for free and open access by the U.S. Department of Agriculture: Agricultural Research Service, Lincoln, Nebraska at DigitalCommons@University of Nebraska - Lincoln. It has been accepted for inclusion in Publications from USDA-ARS / UNL Faculty by an authorized administrator of DigitalCommons@University of Nebraska - Lincoln. 


\title{
Feeding Fitness and Quality of Domesticated and Feral Predators: Effects of Long-Term Rearing on Artificial Diet
}

\author{
Allen Carson Cohen \\ Biological Control and Mass Rearing Research Unit, USDA, ARS, MSA, P.O. Box 5367, Mississippi State, Mississippi 39762 \\ Received January 4, 1999, accepted August 12, 1999
}

\begin{abstract}
Predatory geocorids, Geocoris punctipes Say (Geocoridae: Hemiptera), that had been reared (domesticated) for over 6 years ( 60 continuous generations) on an artificial diet were compared with feral $\left(F_{1}\right)$ counterparts to determine possible domestication-associated losses in predatory capabilities. Using adult female predators provided with either tobacco budworm larvae, Heliothis virescens F., or pea aphids, Acyrthosiphon pisum Harris, as prey, I measured predator weights, handling time with a single prey, amount extracted, consumption rate, and feeding (gut) capacity. Domesticated females were significantly smaller than ferals, weighing $4.53 \mathrm{mg}$ versus $5.09 \mathrm{mg}$, respectively. Domestication did not significantly influence handling times, which averaged 131 (domesticated) and $122 \mathrm{~min}$ (feral) for predators feeding on $\mathrm{H}$. virescens larvae and 106 (domesticated) and $94 \mathrm{~min}$ (feral) for G. punctipes feeding on A. pisum. Although there were significant differences in the weights of the two kinds of prey $(H$. virescens larvae being about twice as heavy as the A. pisum), both prey species exceeded the ingestion capacity of the predators. Amounts extracted by predators were 1.12 to $1.20 \mathrm{mg}$ and were not significantly influenced by rearing background, prey biomass, or prey type. Consumption rates of 11.86 and $12.91 \mu \mathrm{g} / \mathrm{min}$ were nearly identical for both domesticated and feral predators regardless of prey species.

Key Words: entomophagous insects; artificial diets; insect rearing; feeding biology; handling time; gut capacity.
\end{abstract}

\section{INTRODUCTION}

Although there is a great need for integrated pest management compatible technologies, biological control by augmentation of natural enemies has been slow to emerge as a practical tool. Nordlund and Greenberg (1994) and Nordlund (1998) pointed out that inoculative and inundative biological control on a large scale can succeed only if mass production is made technologically possible. These authors further argued that artifi- cial diets are essential to the automation process. Efforts to develop artificial diets for entomophagous insects are not new. In over a half century there have been dozens of reports published on artificial diets for entomophagous insects (Grenier et al., 1994).

Despite accessible information on artificial diets and the fact that over a hundred insectaries market predators and parasites in North America (Hunter, 1994), artificial diets are not used for commercial production of entomophages. Cohen and Smith (1998) explained that this discrepancy between research and commercial use of artificial diets results, in part, from failings in the diets in terms of expense and labor in diet production. But there are insidious reasons that more than 50 years of effort to produce entomophages with artificial diet technology has produced little results. Support for development of this technology and willingness to adopt it have been hampered by a concern in the biological control community about the quality of "unnaturally produced" entomophages (Cohen and Staten, 1994). A monograph by the National Academy of Sciences (1969) articulated the point of view that predators and parasitoids produced on factitious hosts will be less effective or of lower quality than those from natural conditions. These concerns have been subsequently discussed by Bartlett (1984, 1994), Cohen and Staten (1994), and King et al. (1985).

One artificial diet developed for rearing the predator Geocoris punctipes Say (Cohen, 1985a) shows promise for the type of large-scale automated system of production described by Nordlund and Greenberg (1994). It meets the requisite of being inexpensive, costing less than $\$ 3.00$ per kilogram, compared to $\$ 300$ to $\$ 1000$ per kilogram for moth eggs. It has further been used to produce small to moderate sized colonies of $G$. punctipes for an extended period of time (Cohen and Staten, 1994) and thus meets the requisite of supporting colonies that can be produced reliably. However, the issue of quality of predators reared under nonnatural conditions has not yet been addressed for this diet. The feeding adaptations of $G$. punctipes that especially 
qualify it as an excellent generalist predator are discussed by Cohen (1989, 1990, 1996, 1998a, 1998b).

Simply stated, domestication puts insects in a homogeneous environment that lacks the challenges of natural selection. In some instances, there is actually a selection against certain characteristics that would be part of the organism's fitness in nature. As examples of the selection against traits that would confer fitness in nature, Bartlett (1984) discussed the elimination of diapause genes and "startle response" genes. Such inadvertent selection can be exacerbated by founder effect, where small starter population size leads to higher rates of genetic drift.

These pitfalls are a legitimate concern for researchers and biological control practitioners who are interested in the use of augmentative biological control where laboratory cultured entomophages are to be used. This is especially true of potential programs that are to be centered around artificially based augmentation. My personal experience has led me to believe that there is a strong undercurrent of skepticism about the efficacy of artificially produced or otherwise domesticated insects. Recently, for example, a well-known scientist stood up at an international symposium on artificial-based production of natural enemies and said that laboratory-reared predators would become so maladapted that once released into the field, they would sit and wait for a technician to come and feed them artificial diet.

This skepticism is difficult to document concretely because it does not find its way into the technical literature, other than as oblique comments discussed by Cohen and Staten (1994), but I have heard many such comments in my two decades of research on artificial diet-based augmentation of predators. I feel that it is important to put these concerns into a context that will allow them to be tested and discussed with a real database. To this end, I set out to test the potential for deterioration of predator quality in our colony of $G$. punctipes, which at the time of these experiments had been reared on an artificial diet exclusive of insect components for over 60 continuous generations. Because these predators had been provided so long with Parafilm-packaged artificial diet void of insect components, I wanted to determine whether or not they could carry on normal feeding functions that compared with those of their feral counterparts.

To determine their capability as predators, I chose these characteristics of feeding biology: (1) amounts (in milligrams) of prey biomass extracted; (2) handling time (in minutes) (i.e., the total period of contact with prey including attack, prey preparation by extraoral digestion, and ingestion of prey biomass; (3) rate of prey consumption (in micrograms); and (4) relative gut capacity (i.e., the amount of the prey biomass ingested in relationship to the predator's weight, expressed as a percentage). These four parameters are central to predation, to a great extent determining predation capacity. These parameters were reported and discussed by Cohen and Tang (1997) as good measures of predator fitness that could be evaluated objectively. The hypothesis being tested is that rearing predators under artificial conditions will cause a degradation in one or more of these feeding characteristics.

\section{MATERIALS AND METHODS}

All G. punctipes used in this study were collected from an alfalfa farm in Marana about $25 \mathrm{~km}$ northwest of Tucson, Arizona. The feral G. punctipes were the $\mathrm{F}_{1}$ progeny of adults collected about 5 weeks prior to the tests. The offspring of the field-collected adults were reared on $H$. virescens eggs and heat-killed Spodoptera exigua larvae and green beans (Phaseolus vulgarus $\mathrm{L}$.) as described by Cohen and Debolt (1983). The domesticated $G$. punctipes were reared on a beef-product diet described by Cohen (1985a). The colony was started in the summer of 1980 and was changed to artificial diet in December 1983, and these tests were conducted in spring of 1990. The domesticated predators were taken from a production system of more than 60 continuous generations on artificial diet and nearly 90 generations in captivity. The rearing room was held at $27 \pm 1.5^{\circ} \mathrm{C}$, $40 \pm 2 \% \mathrm{RH}$ with a 14:10 h light:dark phase.

Feeding tests were conducted according to the methods described by Cohen and Tang (1997). All G. punctipes used in these tests were females that had completed adult eclosion 1-2 days prior to these tests. Each individual was starved and provided with water in a wet sponge for $24 \mathrm{~h}$ prior to feeding trials. I made these efforts to standardize the predators as much as possible, keeping them at about equal states of egg development, adult age, and degree of gut emptiness. Previous work (Cohen, 1989, 1990) had shown that it takes $G$. punctipes about $24 \mathrm{~h}$ to empty a completely full anterior midgut. Tests were conducted in the rearing room and were begun at 0800 every day.

Five tests were conducted per day, with each test consisting of the following: standardized predators were weighed to the nearest $0.1 \mathrm{mg}$ on a microbalance and placed in a 3.7-cm-diameter petri dish with a preweighed prey. Prey were either 4-day posthatch $H$. virescens larvae that were reared on artificial diet (Patana, 1969) or large pea aphids, Acyrthosiphon siphon Harris (Aphididae: Homoptera), that were reared on Vicia faba L. (Cohen, 1989): Predators that failed to eat within the first $15 \mathrm{~min}$ of exposure to prey were returned to the colony. Predators that did feed were observed constantly for the full feeding bout so that handling time could be noted to the nearest minute. As defined by Kaspari (1990), handling time is the interval between initial contact with prey and the release of 
prey, including capture time, preparation time, and ingestion time (i.e., $H_{\mathrm{t}}=T_{\mathrm{c}}+T_{\mathrm{p}}+T_{\mathrm{i}}$ ). After feeding terminated, predators were allowed another $5 \mathrm{~min}$ to resume feeding. After $5 \mathrm{~min}$ postfeeding, predators were reweighed to determine the amount of biomass extracted from the prey. In cases where the predator eliminated waste during the feeding or postfeeding period, data were discarded. Predators were discarded after feeding so that no repetition of feeding observations could be made on the same individual.

\section{RESULTS}

As has been previously reported (Cohen and Staten, 1994), the domesticated G. punctipes weighed significantly less than feral counterparts of the same age (Table 1). The biomass of the 4-day-old $H$. virescens averaged slightly more than twice that of $A$. pisum. The $H$. virescens were about 1.3 -fold as heavy as the predators, and the A. pisum were about 0.5 -fold the weight of the predators.

Despite the differences in predator weights, the biomass extracted by the domesticated and feral predators was nearly equal (about 1.1-1.3 mg) for both types of prey (Table 2). There were no significant differences between domesticated and feral predators in biomass of aphids extracted $(t=0.61, d f=58, P=0.542)$ or for biomass of $H$. virescens extracted $(t=1.27, d f=58$, $P=0.21$ ). Also, extraction rates were similar (about 11 $\mu \mathrm{g} / \mathrm{min}$ ) for both domesticated and feral predators feeding on $H$. virescens as well as both types of predators feeding on A. pisum (Table 2). There were no significant differences in extraction rates for domesticated versus feral predators consuming aphids $(t=0.62$, $d f=58, P=0.54)$ or $H$. virescens $(t=1.57, d f=58$, $P=0.123$ ) (Table 2). Also, there were no significant differences in means for handling times for domesticated (106 $\pm 6.7 \mathrm{~min})$ versus feral predators consuming aphids $(94 \pm 5.7 \mathrm{~min})(t=1.36, d f=58, P=0.18)$ or for predators consuming $H$. virescens $(131 \pm 6.1 \mathrm{~min}$ for domesticated predators and about $123 \pm 8.2 \mathrm{~min}$ for

\section{TABLE 1}

Weights of Predators (in $\mathrm{mg} \pm \mathrm{SE}$ ) Geocoris punctipes and Prey Heliothis virescens and Acyrthosiphon pisum Used in This Study

\begin{tabular}{llll}
\hline \multicolumn{1}{c}{ Prey } & \multicolumn{1}{c}{$\begin{array}{c}\text { Predator } \\
\text { treatment group }\end{array}$} & $\begin{array}{c}\text { Predator } \\
\text { weight }\end{array}$ & Prey weight \\
\hline H. virescens & Domesticated & $4.53(0.14) \mathrm{b}$ & $6.07(0.47) \mathrm{a}$ \\
H. virescens & Feral & $5.09(0.15) \mathrm{a}$ & $6.36(0.23) \mathrm{a}$ \\
A. pisum & Domesticated & $4.61(0.13) \mathrm{b}$ & $2.76(0.12) \mathrm{b}$ \\
A. pisum & Feral & $5.11(0.11) \mathrm{a}$ & $2.71(0.12) \mathrm{b}$ \\
\hline
\end{tabular}

Note. Thirty randomly selected individuals from each treatment were weighed. Means in a column not followed by the same letter are significantly different, SNK test $(P=0.05)$.

\section{TABLE 2}

Amounts $(\mathrm{mg} \pm \mathrm{SE})$ of Heliothis virescens and Acyrthosiphon pisum Extracted and Rate of Consumption ( $\mu \mathrm{g} /$ min $\pm \mathrm{SE}$ ) by Domesticated and Feral Geocoris punctipes

\begin{tabular}{lllr}
\hline \multicolumn{1}{c}{ Prey } & $\begin{array}{c}\text { Rearing history } \\
\text { of predator }\end{array}$ & $\begin{array}{c}\text { Amount of } \\
\text { prey extracted }\end{array}$ & \multicolumn{1}{c}{$\begin{array}{c}\text { Rate of } \\
\text { extraction }\end{array}$} \\
\hline H. virescens & Domesticated & $1.13(0.091)$ & $9.25(0.863)$ \\
H. virescens & Feral & $1.32(0.12)$ & $11.18(0.876)$ \\
A. pisum & Domesticated & $1.20(0.08)$ & $12.81(1.427)$ \\
A. pisum & Feral & $1.12(0.09)$ & $11.86(0.581)$ \\
\hline
\end{tabular}

Note. Thirty of each group were tested. Means were not significantly different, Student's $t$ test $(P=0.05)$.

feral predators) $(t=0.86, d f=58, P=0.39)$. Estimates of relative gut capacities of $G$. punctipes were between 22.0 and $26.5 \%$. These estimates were based on other parameters already tested statistically (amounts of prey extracted and predator weights), so that no further statistical analysis was made on this parameter.

\section{DISCUSSION}

Two of the most important aspects of predator fitness (and predator quality) are the periods required to meet feeding demands and the amount of nutritional material that the predator can extract from its prey (Cohen and Tang, 1997; Schoener, 1971). Schoener (1971) explained these two aspects of predator feeding as "time minimization" and "energy maximization" and represented them as opposite ends of a continuum of feeding strategies. Because it is difficult to pinpoint whether time minimization or energy (or nutrient) maximization is of greater importance, Cohen and Tang (1997) tested both handling time and biomass uptake, and I followed that convention in this study to evaluate feeding competence and quality in domesticated and feral G. punctipes.

Bartlett (1984, 1994) pointed out that several forces contributed to genetic changes in populations as they undergo domestication. "Founder effect" results from the relatively small size of a laboratory population and is a violation of Hardy-Weinberg equilibrium dynamics. Second, there is a strong selection against any individuals that cannot tolerate laboratory conditions. For the subjects of the present study, there is an obvious selection for individuals that can accept nonmoving food and, furthermore, food that is of noninsect origin (i.e., artificial diet made of vertebrate meat products) and presented in a form that is far removed from that of a real insect (i.e., Parafilm packets). Other artificial aspects of the G. punctipes rearing set-up were the availability of water from sponges rather than from living plants, nectar, or dew, a 14:10 h light:dark period 
throughout the year, a constant temperature of $27^{\circ} \mathrm{C}$, constant humidity of about $50 \% \mathrm{RH}$, flannel cloth as an oviposition site, and countless other more subtle deviations from the predators' natural environment. The laboratory colony tested here, having started from a population of about 1000-3000 field-collected insects, had clearly been put through some strong selective pressures over the $>60$ generations of captivity with artificial diet as their only external (i.e., noncannibalism based) food source.

These facts raise compelling questions about the nature of individuals from the G. punctipes colony with respect to their ability to resume "normal" predatory activities. Several studies that were spawned by these questions were reviewed by Cohen and Staten (1994), and they showed that although domesticated predators were smaller and less fecund than their feral counterparts, both populations showed similar prey selection characteristics (Hagler and Cohen, 1991), similar metabolic efficiencies (Cohen, 1984, 1985b; Cohen and Urias, 1988), and similar digestive abilities when resorting to natural prey (Cohen and Byrne, 1992). Cohen and Staten (1994) and Cohen (unpublished data) demonstrated that domesticated predators fed strictly on artificial diets were able to survive field conditions and consume natural prey. However, in light of the intensity of artificial selection of laboratory-reared predators, it is important to use direct testing of predatory characteristics such as handling time, amounts, and rates of extraction to demonstrate potential losses of predator efficiency. These characteristics would serve as evaluation tools to assess possible losses of quality associated with domestication.

A characteristic used often to evaluate fitness of insects is their body mass or size, and it has been used in several studies of diet efficacy for G. punctipes (Cohen, 1985a; Cohen and Debolt, 1983; Cohen and Staten, 1994). The body mass of the domesticated predators was significantly less (by about 10\%) than that of the feral G. punctipes. Cohen $(1995,1998 b)$ and Cohen and Tang (1997) discussed the importance of relative predator/prey mass in predator feeding ecology, pointing out that hemipterous insects and other predators that use extraoral digestion are especially suited to consuming relatively large prey. Conversely, these authors argued that predators that use extraoral digestion are not well equipped to utilize small prey (less than $10 \%$ of the predator's biomass), which offer little nutrient reward but require a large investment in time and materials to locate, subdue, and extract.

Despite the significant differences in the biomass of the domesticated and feral predators, there were no significant differences in predator quality as indicated by handling time, amounts extracted, and extraction rates. This means that the smaller domesticated predators were able to extract essentially the same amounts that their larger counterparts extracted. Also, the rates of extraction were not influenced by the relative size differences between the domesticated and the feral $G$. punctipes. Because handling time was measured as total contact time between the predator and the prey, it does not resolve the components of time required to subdue prey and postkill feeding time. Further experiments with time required to subdue prey separated from feeding time would further our understanding of the role of relative predator/prey size in the ecology of predators.

The only deficiency in quality of domesticated predators shown in this study was in size (or biomass). Based on preliminary observations (Cohen, unpublished results), this deficiency is possibly not a genetic trait because replacement of artificial diet with natural prey such as lepidopteran eggs resulted in production of larger predators from the domesticated stock. This issue deserves future attention, especially in light of previous studies (Cohen, 1985a; Cohen and Staten, 1994) that indicate that domesticated $G$. punctipes produce fewer eggs when fed artificial diet instead of insect eggs. However, the direct feeding characteristics measured here showed parity between the domesticated and the feral predators. The absence of deterioration of G. punctipes after domestication on an artificial diet may be related to the somewhat "tame" feeding habits of these predators. They are known, for example, to use plant materials and slow- or nonmoving prey such as aphids and insect eggs (Tamaki and Weeks, 1972). This feature of their natural history may preadapt them to feeding on a nonmoving artificial diet. Presentation of the diet in stretched Parafilm may simulate the surface of both host plants and prey that G. punctipes naturally accept as nutrient sources. The stretched Parafilm has creases and protrusions that evidently mimic the natural feeding surfaces to which these predators are accustomed. The artificial diet was designed to mimic the nutritional composition and texture of the contents of lepidopteran eggs (Cohen, 1985a, 1992), so it probably did not require a great amount of adaptation or selection for $G$. punctipes to adapt to the diet, and it evidently did not require special adjustment to revert to natural prey. These factors may be important considerations in future work on rearing conditions, especially artificial diets, for entomophagous arthropods.

\section{ACKNOWLEDGMENTS}

I thank Robert Tang and Sonja Johnson for their technical assistance and Frank Davis, Alan Bartlett, and D. A. Nordlund for their helpful reviews of an earlier version of this work.

\section{REFERENCES}

Bartlett, A. C. 1984. Genetic changes during insect domestication. In "Advances and Challenges in Insect Rearing" (E. G. King and N. C. Leppla, Eds.), pp. 2-8. USDA, ARS, New Orleans, LA. 
Bartlett, A. C. 1994. Maintaining genetic diversity in laboratory colonies of parasites and predators. In "Applications of Genetics to Arthropods of Biological Control Significance” (S. K. Narang, A. C. Bartlett, and R. M. Faust, Eds.), pp. 134-145. CRC Press, Boca Raton, FL.

Cohen, A. C. 1984. Food consumption, food utilization and metabolic rates of Geocoris punctipes (Het.: Lygaeidae) fed Heliothis virescens (Lep.: Noctuidae) eggs. Entomophaga 29, 361-367.

Cohen, A. C. 1985a. Simple method for rearing the insect predator Geocoris punctipes (Heteroptera: Lygaeidae) on a meat diet. $J$. Econ. Entomol. 78, 1173-1175.

Cohen, A. C. 1985b. Metabolic rates of two hemipteran members of a predator-prey complex. Comp. Biochem. Physiol. 81A, 833-836.

Cohen, A. C. 1989. Ingestion efficiency and protein consumption by a heteropteran predator. Ann. Entomol. Soc. Amer. 82, 495-499.

Cohen, A. C. 1990. Feeding adaptations of some predaceous Hemiptera. Ann. Entomol. Soc. Am. 83, 1215-1223.

Cohen, A. C. 1992. Using a systematic approach to develop artificial diets for predators. In "Advances in Insect Rearing for Research and Pest Management." (T. E. Anderson and N. C. Leppla, Eds.), pp. 77-91. Westview Press. Boulder, Co.

Cohen, A. C. 1995. Extra-oral digestion in predatory arthropods. Annu. Rev. Entomol. 40, 85-103.

Cohen, A. C. 1996. Plant feeding by predatory Hemiptera: Evolutionary and adaptational aspects of trophic switching. In "Biological Control by Predatory Hemiptera" (R. Wiedenmann, O. Alomar, and D. Livingstone, Eds.), pp. 1-17. Thomas Say Publications in Entomology, Entomol. Soc. Am., Lanham, MD.

Cohen, A. C. 1998a. Biochemical and morphological dynamics and predatory feeding habits in terrestrial Heteroptera. In "Predatory Heteroptera: Their Ecology and Use in Biological Control" (M. Coll and J. R. Ruberson, Eds.), pp. 21-32. Thomas Say Publications in Entomology, Entomol. Soc. Am., Lanham, MD.

Cohen, A. C. 1998b. Solid-to-liquid feeding: The inside(s) story of extra-oral digestion in predaceous Arthropoda. Am. Entomol. 44, 103-116.

Cohen, A. C., and Byrne, D. N. 1992. Geocoris punctipes as a predator of Bemisia tabaci: A laboratory evaluation. Entomol. Exp. Appl. 64, 195-202.

Cohen, A. C., and Debolt, J. W. 1983. Rearing Geocoris punctipes on insect eggs. Southwest. Entomol. 8, 61-64.

Cohen, A. C., and Smith, L. K. 1998. A new concept in artificial diets for Chrysoperla ruilabris: The efficacy of solid diets. Biol. Control 13, 49-54.

Cohen, A. C., and Staten, R. T. 1994. Long-term culturing and quality assessment of predatory big-eyed bugs, Geocoris punctipes. In "Applications of Genetics to Arthropods of Biological Control Significance" (S. Karl Narang, A. C. Bartlett, and R. M. Faust, Eds.), pp. 122-132. CRC Press, Boca Raton, FL.

Cohen, A. C., and Tang, R. 1997. Relative prey weight influences handling time and extracted biomass in predatory hemipterans. Environ. Entomol. 26, 559-565.

Cohen, A. C., and Urias, N. M. 1988. Nutritional indices of a predator Geocoris punctipes (Heteroptera: Lygaeidae) fed artificial diets with rutin. J. Entomol. Sci. 23, 174-179.

Grenier, S., Greany, P., and Cohen, A. C. 1994. Potential for mass release of insect parasitoids and predators through development of artificial culture techniques. In "Pest Management in the Subtropics: Biological Control: A Florida Perspective" (D. Rosen, F. D. Bennett, and J. Capinera, Eds.), pp. 181-295. Intercept Press, Andover, UK.

Hagler, J. R., and Cohen, A. C. 1991. Prey selection by in vitro- and field-reared Geocoris punctipes. Entomol. Exp. Appl. 59, 201-205.

Hunter, C. D. 1994. "Suppliers of Beneficial Organisms in North America," Department of Pesticide Regulation Publication PM 94-3. California Environmental Protection Agency, Sacramento, CA.

Kaspari, M. 1990. Prey preparation and the determinants of handling time. Anim. Behav. 40, 118-126.

King, E. G., Hopper, K. R., and Powell, J. E. 1985. Analysis of systems for biological control of crop arthropod pests in the U.S. by augmentation of predators and parasites.In "Biological Control in Agricultural IPM Systems" (M. A. Hoy and D. C. Herzog, Eds.), pp. 201-227. Academic Press, Orlando, FL.

National Academy of Sciences. 1969. Control by parasites, predators, and competitors. In "Insect-Pest Management and Control," pp. 100-164. Nat. Acad. Sci., Washington, DC.

Nordlund, D. A. 1998. Capacity and quality: Keys to success in the mass rearing of biological control agents. In "Natural Enemies of Insects." Guangdong Entomological Society, 20(4), 169-179.

Nordlund, D. A., and Greenberg, S. M. 1994. Facilities and automation for the mass production of arthropod predators and parasitoids. Biocontrol News Inform. 4, 45-49.

Patana, R. 1969. "Rearing Cotton Insects in the Laboratory." U.S. Department of Agriculture Production Research Report 108. p. 6.

Schoener, T. W. 1971. Theory of feeding strategies. Annu. Rev. Ecol. Syst. 2, 369-404.

Tamaki, G., and Weeks, R. E. 1972. Biology and ecology of two predators Geocoris punctipes Say and G. bullatus Stal. USDA Technical Bulletin 1446. p. 46. 